\title{
The medical relevance of Spirometra tapeworm infection in Indonesian Bronzeback snakes (Dendrelaphis pictus): A neglected zoonotic disease
}

\author{
Aditya Yudhana ${ }^{1}$, Ratih Novita Praja ${ }^{2}$ and Arif Supriyanto ${ }^{3}$
}

1. Department of Parasitology, Faculty of Veterinary Medicine, Airlangga University, Indonesia; 2. Department of Microbiology, Faculty of Veterinary Medicine, Airlangga University, Indonesia; 3. Department of Wildlife Conservation, Education Staff of Mojokerto Reptile and Exotic Animals Community, Indonesia.

Corresponding author: Aditya Yudhana, e-mail: adityayudhana@fkh.unair.ac.id

Co-authors: RNP: ratihnovitapraja@fkh.unair.ac.id, AS: ariefmaverick412@gmail.com

Received: 04-01-2019, Accepted: 03-05-2019, Published online: 18-06-2019

doi: 10.14202/vetworld.2019.844-848 How to cite this article: Yudhana A, Praja RN, Supriyanto A (2019) The medical relevance of Spirometra tapeworm infection in Indonesian Bronzeback snakes (Dendrelaphis pictus): A neglected zoonotic disease, Veterinary World, 12(6): 844-848.

\begin{abstract}
Aim: Spirometra parasites cause sparganosis, a zoonotic disease, especially in reptiles and humans. This study aimed to report on the prevalence and effects of Spirometra parasites infection on public health and provide a scientific foundation for its prevention.

Materials and Methods: A total of 378 living Indonesian wild-caught and captive-bred Bronzeback snakes (Dendrelaphis pictus) were selected. The snakes were euthanized using ethyl ether anesthesia before checking for Spirometra parasites. The numbers of Spirometra located in the muscle tissue, subcutaneous tissue, and coelom (including the viscera) were each counted to investigate the distribution of Spirometra inside the snake body cavity.
\end{abstract}

Results: The total prevalence in the sample was $50.85 \%$. The prevalence values in wild-caught and captive-bred snakes were $70.7 \%$ and $48.7 \%$, respectively. More than half $(56.6 \%)$ of the Spirometra parasites were located in the muscular tissue, while $29.5 \%$ were in the subcutaneous tissue and $13.8 \%$ were in the coelomic cavity.

Conclusion: Wild-caught Indonesian Bronzeback snakes, which are sold as food in markets, and captive-bred snakes, which are collected as exotic pets in Indonesia, have similar opportunities to transmit the Spirometra parasite and cause global health problems due to their high prevalence.

Keywords: Dendrelaphis pictus, sparganosis, Spirometra, zoonosis.

\section{Introduction}

In current times, reptiles are threatened by factors influencing extinction, such as habitat loss, environmental pollution, infectious diseases, unexpected uses, and global climate change [1]. One of these endangered reptiles is the snake. Snakes are one of the several types of reptiles whose existence is protected by government law. Snakes are also included in the group of exotic animals that have been hunted to be sold or domesticated. This animal plays an important role in maintaining ecosystem stability [2]. Dendrelaphis pictus, more commonly known as the Indonesian Bronzeback snake, has a wide distribution, extending from the Western to Eastern regions of Indonesia with origins in the province of East Java. Nowadays, the Indonesian Bronzeback snakes from East Java are included in snake species who face extinction [3]. Various environmental threats have not only reduced the snake population but also increased health problems such as parasitic diseases

Copyright: Yudhana, et al. Open Access. This article is distributed under the terms of the Creative Commons Attribution 4.0 International License (http://creativecommons.org/licenses/ by/4.0/), which permits unrestricted use, distribution, and reproduction in any medium, provided you give appropriate credit to the original author(s) and the source, provide a link to the Creative Commons license, and indicate if changes were made. The Creative Commons Public Domain Dedication waiver (http:// creativecommons.org/publicdomain/zero/1.0/) applies to the data made available in this article, unless otherwise stated. from tapeworm infections [4]. Sparganosis is a parasitic disease in snakes caused by the infective stage of Spirometra tapeworms; it is a zoonotic disease, which means it can be transmitted to humans and cause clinical signs such as allergic reaction, chronic inflammation, and painful nodules within subcutaneous tissues [5].

Sparganosis is an infection of humans and animals caused by plerocercoid larvae (spargana) originating from various diphyllobothroid tapeworms belonging to the genus Spirometra [6]. Spargana live in frogs and snakes who serve as the second intermediate hosts of Spirometra, but they can also infect humans, pigs, rodents, and birds who serve as other intermediate or paratenic hosts. Carnivores, such as dogs and cats, serve as the final hosts of Spirometra, which parasitize in their small intestines [7]. Moreover, parasitic disease in wildlife may have a significant influence on domestic animals and humans. One of the possible sources of infection is the consumption of meat of wild animals, such as snakes that enable circulation of infectious agents in the environment and their transmission to humans and domesticated animal hosts. Spirometra tapeworm has become one of the most neglected parasitic agents with zoonotic potential [8].

To the best of our knowledge, there have been no studies about Spirometra parasite infection in Indonesian Bronzeback snakes. Therefore, we aimed 
to report about the prevalence and public health effects of Spirometra infection and provides a scientific foundation for preventing sparganosis, to further our understanding of its medical relevance.

\section{Materials and Methods}

\section{Ethical approval}

This study was conducted with permission from the local reptile community and wildlife conservation department in East Java Province, Indonesia. This study was reviewed and approved by the Animal Care and Use Committee of Faculty of Veterinary Medicine, Universitas Airlangga, number 713-KE.

\section{Sampling}

A total of 378 living Indonesian wild-caught and captive-bred Bronzeback snakes were selected from the reptile market in Mojokerto City, East Java Province, Indonesia (112.434084 Longitude and -7.472638 Latitude). Snake species were identified according to their morphological characteristics. D. pictus snakes were characterized by their head color ranging from brown to bronze at the top; further, a black eye-stripe extends along the neck for a short distance down the body. In addition, there was a cream and black stripe along the flanks. The larger vertebral scales, which run along the full length of the body, may be brown or olive gray. When threatened or when consuming prey, this snake inflates its body slightly to reveal bluish or turquoise skin underlying its body scales. The head was slightly larger than its moderately slender body, and its eyes were large, typically with a brown iris. The snakes were kept in the Reptile Rescue Center by the local reptile community management. We conducted this work with permission from the local reptile community and wildlife conservation department. The live snakes were euthanized using ethyl ether anesthesia before checking for Spirometra parasites. Spirometra was identified by its tape-like morphology with a white colored, long, flat, and segmented body form.

The snakes were dissected to examine for infection from Spirometra parasites. Their body length and weight were measured before the dissection. For each snake, the body was peeled from the neck to the top of the tail, and then, we isolated the visceral masses from the esophagus and trachea to the cloaca. Then, the numbers of Spirometra located in the muscle tissue, subcutaneous tissue, and coelom (including viscera) were each counted to investigate the distribution of Spirometra inside the snake body.

\section{Statistical analysis}

The data were processed using Software SPSS v21 (IBM, USA). In addition, the non-parametric Kruskal-Wallis test was used to compare the difference in the numbers of parasites among the muscle tissues, subcutaneous tissues, and coeloms of the snakes.

\section{Results}

The body length of the Indonesian Bronzeback snakes ranged from 13 to $132 \mathrm{~cm}$ and the body weight ranged from 2.1 to $1550.0 \mathrm{~g}$. Essential information, including source; number of samples; and age, body length, and weight of each snake, is shown in Table-1. Overall, Spirometra tapeworms were isolated from 378 snakes, and the total prevalence was $50.85 \%$ in the total examined snake samples. The prevalence of wild-caught snakes and captive-bred snakes was $70.7 \%$ and $48.7 \%$, respectively (Table- 2 ). The macroscopic morphology of Spirometra, which infects different tissues, is shown in Figure-1.

More than half $(56.6 \%)$ of the Spirometra parasites were located in muscular tissue of the snakes, while $29.5 \%$ were in the subcutaneous tissue and $13.8 \%$ were in the coelomic cavity (Figure-2). The non-parametric test showed that the density distributions among the muscle tissue, subcutaneous tissue, and coelom were significantly different $(\mathrm{p}<0.05)$ (Table-2, Figure-2). The prevalence and infection intensities of Spirometra were different according to snake age and source (Figure-2). Wild-caught snakes had higher prevalence and infection intensities compared to captive-bred snakes. Wildcaught snakes in the juvenile age group had the highest prevalence $(92.7 \%)$ compared to $34.6 \%$ in the baby age group and $58.3 \%$ in the adult age group. Captive-bred snakes also recorded a higher prevalence $(61.5 \%)$ in the juvenile age group compared to $15 \%$ in the baby age group and $43 \%$ in the adult age group.

\section{Discussion}

Indonesian Bronzeback snakes have not only become popular as exotic pets in Indonesia but also as raw food for human consumption. Indonesian Bronzeback snakes collected in this study belong to the Colubridae family and are mostly sold in reptile or food markets throughout Asia [9]. Spargana or larvae of Spirometra found in this study have a fairly high prevalence $(50.85 \%)$ in the wild-caught and captive-bred Indonesian Bronzeback snakes collected as samples in this study, which indicates that more than half of the snakes are infected by spargana. Similar results were obtained in studies in other areas and other

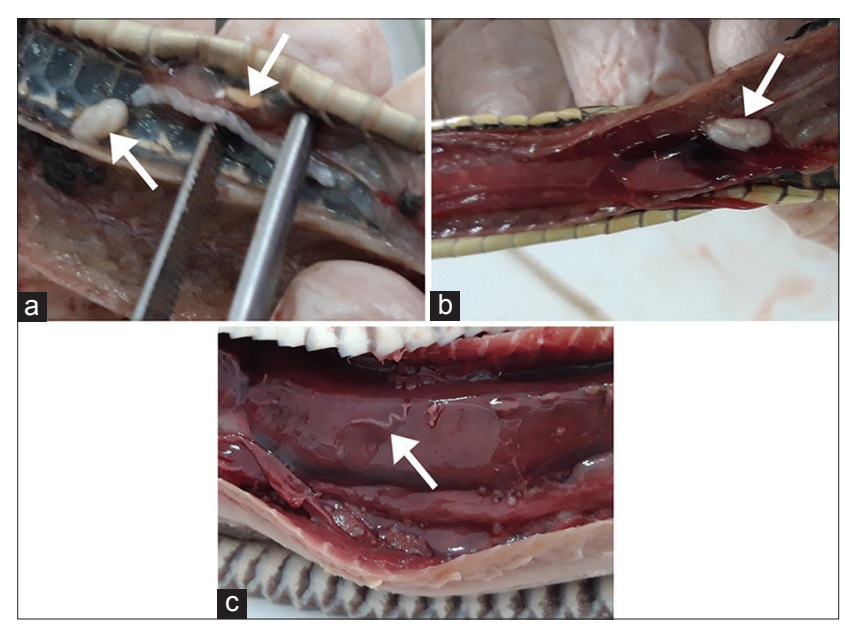

Figure-1: Spirometra located in (a) subcutaneous tissue, (b) coelom, and (c) muscle of Dendrelaphis pictus. Arrows point to Spirometra. 
Table-1: Essential information about the 378 wild-caught and captive-bred snake samples from reptile markets in Mojokerto City, East Java Province, Indonesia.

\begin{tabular}{|c|c|c|c|c|c|c|}
\hline Species of snakes & $\begin{array}{l}\text { Source of } \\
\text { samples }\end{array}$ & $\begin{array}{l}\text { Number of } \\
\text { samples }\end{array}$ & $\begin{array}{l}\text { Range of body } \\
\text { length }(\mathrm{cm})\end{array}$ & $\begin{array}{l}\text { Medians of body } \\
\text { length }(\mathrm{cm})\end{array}$ & $\begin{array}{l}\text { Range of body } \\
\text { weight (g) }\end{array}$ & $\begin{array}{c}\text { Medians of } \\
\text { body weight }(\mathrm{g})\end{array}$ \\
\hline \multicolumn{7}{|l|}{$\begin{array}{l}\text { Dendrelaphis pictus } \\
\text { *Wild-caught }(\mathrm{N}=181)\end{array}$} \\
\hline Baby (1-3 months) & Mojokerto & 26 & $13-32$ & 28 & $2.1-5.6$ & 3.6 \\
\hline Juvenile (3-6 months) & Mojokerto & 83 & $42-84$ & 73 & $150.5-403.6$ & 327.8 \\
\hline Adult (6-9 months) & Mojokerto & 72 & $96-110$ & 105 & $564.8-1301$ & 1105.1 \\
\hline \multicolumn{7}{|c|}{ *Captive breed $(\mathrm{N}=197)$} \\
\hline Baby (1-3 months) & Mojokerto & 20 & $18-52$ & 48 & $5.5-10.6$ & 8.3 \\
\hline Juvenile (3-6 months) & Mojokerto & 91 & $72-96$ & 83 & $607.5-836.6$ & 726.8 \\
\hline Adult (6-9 months) & Mojokerto & 86 & $113-132$ & 125 & $957.8-1550$ & 1458.9 \\
\hline Total samples & & 378 & & & & \\
\hline
\end{tabular}

Table-2: Prevalence, intensity, and locations of Spirometra infections found in wild-caught and captive-bred snake samples from reptile markets in Mojokerto City, East Java Province, Indonesia.

\begin{tabular}{|c|c|c|c|c|c|c|}
\hline \multirow{2}{*}{$\begin{array}{l}\text { Species of snakes } \\
\text { Wild-caught and captive } \\
\text { breed snakes }\end{array}$} & \multicolumn{3}{|c|}{ Infection of Spirometra } & \multicolumn{3}{|c|}{ Locations of Spirometra } \\
\hline & Prevalence (\%) & $\begin{array}{l}\text { Intensity } \\
\text { of infection }\end{array}$ & $\begin{array}{l}\text { Mean intensity } \\
\text { of infection }\end{array}$ & $\begin{array}{c}\text { Subcutaneous } \\
\text { tissue }\end{array}$ & Coelom & Muscle \\
\hline \multicolumn{7}{|l|}{$\begin{array}{l}\text { Dendrelaphis pictus } \\
* \text { Wild-caught }(N=181)\end{array}$} \\
\hline Baby (1-3 months) & 34.6 & $0-23$ & 8.2 & 7 & 3 & 14 \\
\hline Juvenile (3-6 months) & 92.7 & $0-111$ & 14.3 & 213 & 154 & 458 \\
\hline Adult (6-9 months) & 58.3 & $0-87$ & 11.8 & 198 & 56 & 317 \\
\hline \multicolumn{7}{|l|}{ *Captive breed $(\mathrm{N}=197)$} \\
\hline Baby (1-3 months) & 15.0 & $0-7$ & 0.3 & 2 & 0 & 4 \\
\hline Juvenile (3-6 months) & 61.5 & $0-68$ & 13.3 & 63 & 31 & 179 \\
\hline Adult (6-9 months) & 43.0 & $0-43$ & 9.6 & 89 & 24 & 124 \\
\hline Total & & & & 572 & 268 & 1096 \\
\hline Mean & 50.85 & $0-56.5$ & 9.6 & 3 & 2 & 7 \\
\hline
\end{tabular}

A Kruskal-Wallis test showed a significant difference among the number of Spirometra infections in the subcutaneous tissue, coelom, and muscle $(p<0.05)$.

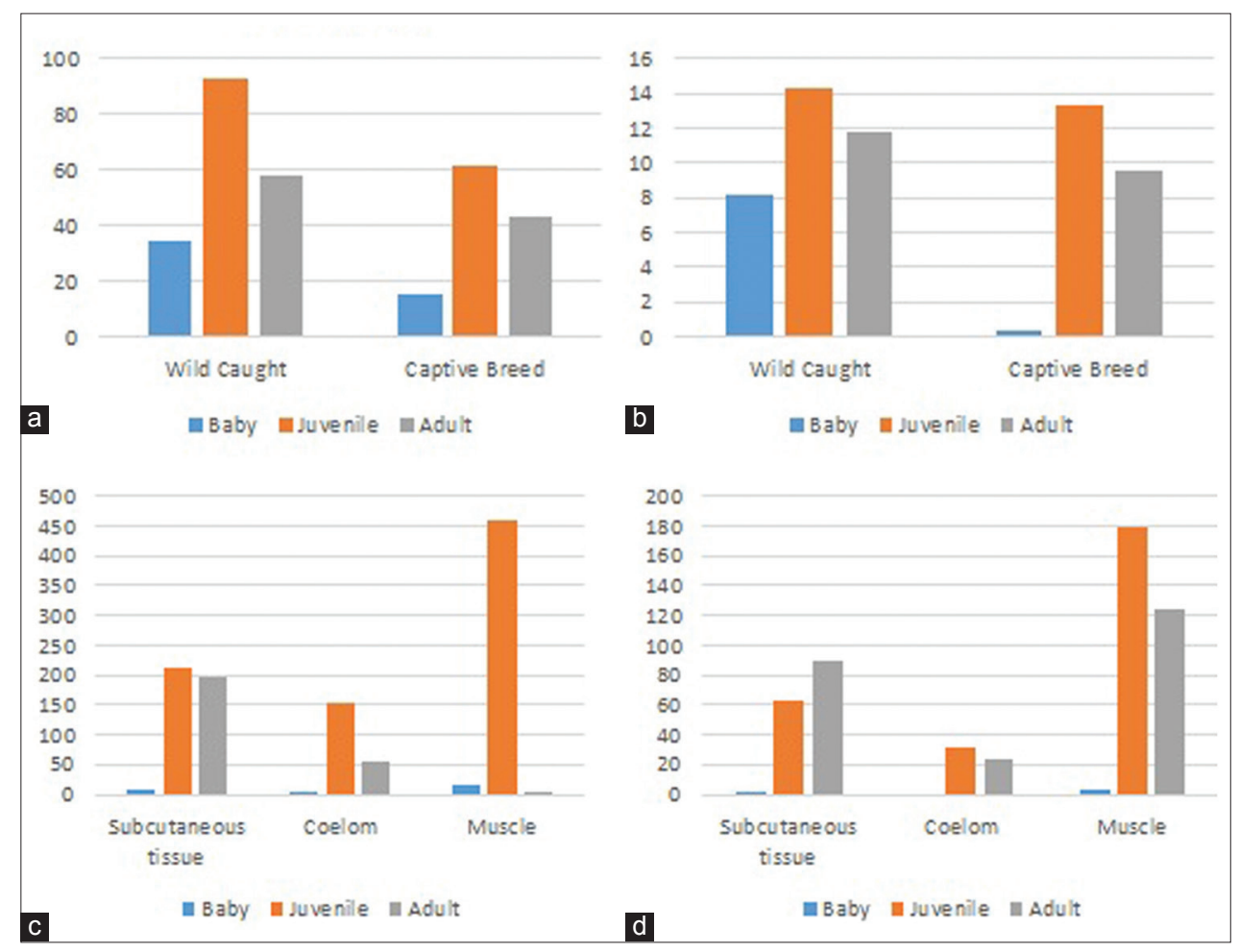

Figure-2: (a) Prevalence of Spirometra, (b) intensity of Spirometra infection, (c) number of Spirometra found in wild-caught snakes, and (d) number of Spirometra found in captive-bred snakes. 
species of snakes [10]. The type of diet commonly consumed by snakes will also usually affect the prevalence of Spirometra infection. Wild-caught snakes are usually infected from consuming frogs as a food source. Due to this, the wild-caught snakes in food markets in China are generally infected by spargana, which spreads to different tissues such as subcutaneous tissues, the coelom, and muscles of snakes [11]. Spargana infection was also reported in two Russell viper snakes from Chennai Snake Park Trust, India, during a gross examination method revealing spargana in the subcutaneous tissue of the snakes [12]. Due to the high prevalence of infection in snakes, snake consumption poses a great risk for human sparganosis because the spargana not only cause parasitic diseases in snakes but also in humans.

Throughout Asia, several cases of sparganosis have been reported in humans and reptiles. Sparganosis in reptiles, including snakes, has also been globally reported, with a high prevalence in several Asian countries, such as South Korea, Japan, Thailand, and China [13]. The occurrence of snakes as the main source of human sparganosis in Korea was due to consumption of snake meat for daily food [14]. In China, there are many cases of human sparganosis caused by eating raw meat from snakes and frogs, drinking snake blood, and swallowing snake gall bladders. Using improper cooking methods for snakes also increase the risk of infection. In addition, Spirometra may contaminate food during the process of cooking snake meat. In a recent report from 2011, a human patient suffered from bronchial sparganosis because he had a history of ingesting raw frogs, snakes, and drinking raw snake blood [15]. Another case of cerebral sparganosis was reported the next year, in 2012, from eating frogs and snakes [16]. Another recent report showed 104 cases of human sparganosis from 2000 to 2006, and more than half, or $53.9 \%$, of cases were caused by eating snakes or frogs [17].

When humans are infected by Spirometra larvae, commonly known as spargana, the larvae can perform visceral migration, infect many tissues, and develop into the mature stage. Subcutaneous sparganosis is the most common form among sparganosis in humans. Spargana has also been reported to migrate into subcutaneous tissues and peripheral muscles such as abdominal walls, lower extremities, scrotums, and chest walls. Under the skin, the lesions look like rubbery and irregular lumps or nodules of 1-2 cm long that resemble a lipoma or fibroma, while causing itchiness, inflammation, and pain. Some infected patients have had chronic forms, and sometimes, the nodules can switch from one tissue to another [18]. Consumption of raw meat or any half-cooked snake biological products can increase the risk of sparganosis. The larvae of Spirometra are very soft and thin, and people generally do not closely examine them, so they conclude that snake meat that is prepared as food is in a condition of proper hygiene and is safe to serve as a food source. From this, snake meat is suspected of playing a role in sparganosis transmission, which is related to human sparganosis.

In this study, the prevalence and intensity of Spirometra infection have been different among various snake age groups. We found interesting data that D. pictus of juvenile age have the highest prevalence and intensity of infection compared to baby and adult age groups. Theoretically, snakes in the baby age group are more susceptible to parasite infections. However, juvenile snakes may have larger and longer bodies, so they also have wider range to hunt the prey, on mainly frogs, which play a role as the intermediate host of Spirometra. Juvenile snakes also have immunity against infection, but they are not as stable as adult snakes, which more frequently adapt to infectious diseases in wild environments. As a result, we infer that snakes in the juvenile age group may have a higher risk of infection to Spirometra, and it would be beneficial to conduct further studies on this topic.

There seems to be a relation between Spirometra infection and the feeding habits of snakes. In general, snakes in wild environment prefer to prey on frogs as a food source and these habits may lead to Spirometra infection [7]. Our investigation is also in accordance with previous studies because wild-caught snakes have higher prevalence and intensity of infection compared to captive-bred snakes. Wild-caught snakes are usually collected and sold in markets as traditional food sources for humans. However, consuming snake meat as a traditional habit occurs in multiple Asian countries, which is related to numerous sparganosis cases reported in China [19]. A previous study reported that snakes and other wild-caught animals have resulted in numerous cases of human sparganosis [17]. Therefore, it is necessary to strengthen food safety and food security policies so that the transmission of human sparganosis from wild animals, such as snakes, can be prevented early on and the risk of infection can be minimized. Moreover, to the best of our knowledge, there is no data or report about Spirometra infection in D. pictus, as well as, there is no report about the spread and prevalence of the infection in Indonesia. To further understand the causes of Spirometra infection in snakes, more detailed surveys on the habitats and dietary habit of these snakes are necessary.

\section{Conclusion}

In this present study about Spirometra infection in D. pictus, we indicated that wild-caught snakes, which are sold as food in markets, and captive-bred snakes, which are collected as exotic pets in Indonesia, have similar opportunities for Spirometra infection and both cause public health problems due to their high infection prevalence. Based on this present study, we also suggest some prevention measures for sparganosis in human and animals such as publishing scientific data about the epidemiology and harm of sparganosis and applying government and local laws to strengthen 
and effectively control and monitor the illegal trade of wild-caught snakes in food markets. Moreover, further studies on the occurrence of sparganosis in wildlife and Spirometra identification through molecular avenues can be conducted to globally complete the prevalence data and increase the public awareness of a neglected zoonotic disease.

\section{Authors' Contributions}

AY is a supervised and project leader. AY is a data analysis and collected samples and RNP carried out dissection of snake samples. AS carried out the collection of snake samples. All authors contributed to the drafting and revision of the manuscript. All authors read and approved the final manuscript.

\section{Acknowledgments}

The authors would like to thank all members of Reptile Rescue Community and Laboratory assistant in the Department of Veterinary Parasitology for their help during the investigation and paper preparation. This work was supported financially by the Faculty of Veterinary Medicine, Airlangga University, Indonesia (RKAT PSDKU Grant no.1185/UN3/2018).

\section{Competing Interests} interests.

The authors declare that they have no competing

\section{Publisher's Note}

Veterinary World remains neutral with regard to jurisdictional claims in published institutional affiliation.

\section{References}

1. Solomon, N.U., James, I.M., Alphonsus, N.O. and Nkiruka, R.U. (2015) A review of host-parasite relationships. Ann. Res. Rev. Biol., 5(5): 372-385.

2. Hill, A.G., Ladds, P.W. and Spratt, D.M. (2014) Acanthocephalan infection and sparganosis in a green tree snake (Dendrelaphis punctulata). Aust. Vet. J., 92(9): 362-364

3. How, R.A., Schmitt, L.H. and Maharadatunkamsi, I. (1996) Geographical variation in the genus Dendrelaphis (Serpentes: Colubridae) within the islands of South-Eastern Indonesia. J. Zool., 238(2): 351-363.

4. Soheir, A.H.R., Mohey, E.Z., El-Latif A., Nadia, I.M. and Obaida, F.E. (2015) Description of some acanthocephalan species from some reptiles in Qena governorate. J. Pharm. Biol. Sci., 10(2): 31-36.

5. Zhou, P., Chen, N., Zhang, R.L., Lin, R.Q. and Zhu, X.Q. (2008) Foodborne parasitic zoonoses in China: Perspective for control. Trends Parasitol., 24(4): 190-196.

6. Pampiglione, S., Fioravanti, M.L. and Rivasi, F. (2003) Human sparganosis in Italy. Case report and review of the European cases. APMIS, 111(3): 349-354.

7. Magnino, S., Colin, P. and Dei-Cas, E. (2009) Biological risks associated with consumption of reptile products. Int. J. Food Microbiol., 134(3): 163-175.

8. Marta, K., Sobocinska, J. and Mariusz, M. (2018) Sparganosis-neglected zoonosis and its reservoir in wildlife. Med. Weter., 74(4): 224-227.

9. Gong, S.P., Hu, H.J. and Shi, H.T. (2007) Surveys of Amphibia and Reptilia in the Qiaoxi Market, Huizhou, Guangdong Province, China. Proceedings of the Zoological Society of Guangdong Province, China, p90.

10. Wang, F., Zhou, L. and Gong, S. (2011) Severe infection of wild-caught snakes with Spirometra erinaceieuropaei from food markets in Guangzhou, China involves a risk for zoonotic sparganosis. J. Parasitol., 97(1): 170-171.

11. Wang, F., Li, W., Hua, L., Gong, S., Xiao, J., Hou, F. and Yang, G. (2014) Spirometra (Pseudophyllidea, Diphyllobothriidae) severely infecting wild-caught snakes from food markets in Guangzhou and Shenzhen, Guangdong, China: Implications for public health. Sci. World J., 2014(1): 1-6.

12. Kavitha, K.T., Latha, B.R., Sundar, S.B., Sridhar, R. and Basith, S.A. (2014) Sparganosis in Russell's viper snake: A case report. J. Parasit. Dis., 38(4): 394-395.

13. Li, M.W., Song, H.Q., Li, C., Lin, H.Y., Xie, W.T., Lin, R.Q. and Zhu, X.Q. (2011) Sparganosis in mainland China. Int. J. Infect. Dis., 15(3): 154-156.

14. Jeon, H.K., Park, H., Lee, D., Choe, S., Kim, K.H., Huh, S., Sohn, W.M., Chai, J.Y. and Eom, K.S. (2015) Human infections with Spirometra decipiens plerocercoids identified by morphologic and genetic analyses in Korea. Korean $J$. Parasitol., 53(3): 299-305.

15. Chen, X.H. (2012) A Case Report of Bronchial Sparganosis Mansoni and Literature Review M.S. Thesis. Guangxi Medical University, Guangxi, China.

16. Zhu, X.Z., Ma, A. and Wang, Y. (2012) Report of a case of cerebral sparganosis. Mod. Pract. Med., 24(1): 1313.

17. Wu, Z.J., Chen, Y. and Qiu, X.L. (2007) An investigation of plerocercoid infection of frogs in Guiyang city and analysis of clinical characteristics of 104 cases. J. Guiyang Med. Coll., 32(1): 140-141.

18. Xie, X.B., Peng, L.K., Peng, F.H., Wang, Y., Lan, G.B. and Yu, S.J. (2010) Sparganosis mansoni in adipose capsule of the living related donor in one case. J. Clin. Rehabil. Tissue Eng. Res., 14(5): 906-908.

19. Xu, L., Meng, M. and Yin, F. (2007) Information on the Trade in Wild Animals and Plants in China. TRAFFIC East Asia-China Programme, WWF-China. p12. 